Rheumatoid Arthritis Clinical

Benefits from Abatacept, Cytokine Blockers, and Rituximab Are All Linked to Modulation of Memory

\section{B Cell Responses}

Abatacept (ABA) is a biologic agent with great proven efficacy in patients with rheumatoid arthritis (RA) ${ }^{1}$. At a molecular level, ABA is composed of recombinant domains of cytotoxic T lymphocyte-associated antigen 4 (CTLA-4), fused to the constant region domains of human IgG1, which serves to increase in vivo half-life. This agent binds to CD80/CD86 with a much higher avidity than the CD28 on many $\mathrm{T}$ cells, and therefore can act as a physiologic competitive inhibitor that interrupts cell-cell co-stimulatory interactions. In earlier reports, ABA treatment of patients with RA was shown to have striking effects on the modulation of $\mathrm{T}$ cell subsets ${ }^{2}$.

The recent report by Scarsi, et al highlights the bidirectional nature of the CD28-CD80/86 interaction and the profound effects that $\mathrm{ABA}$ can have on the $\mathrm{B}$ cell compartment of the immune system, especially for memory $\mathrm{B}$ cells ${ }^{3}$. With the proven efficacy of the B cell-targeted anti-CD20 agent rituximab (RTX), the central roles of B cells in RA have become well accepted, and B cells also commonly express the co-stimulatory molecules CD $80 / 86^{4}$. Even at the earliest onset of clinical signs and symptoms, patients with RA display dysregulated immune-cell trafficking and maturation. Compared to healthy subjects, patients with RA also have abnormal levels of circulating memory B cells (identified by CD27 expression), and this may in part reflect their recruitment to the synovial compartment or secondary lymph nodes ${ }^{5}$.

In a small study of 28 patients with RA, Scarsi, et al showed that after 6 months of ABA treatment, patients with clinical responses had significant decreases in levels of switched memory B cells, with persistent decreases in memory B cell subsets also found at 12 months $^{3}$. ABA therapy also significantly reduced levels of serum total $\mathrm{IgG}$, IgA, and IgM, reflecting a reversal of disease-associated hypergammaglobulinemia. There were also significant decreases in anticitrullinated protein antibody (ACPA) $\operatorname{IgG}$ and $\operatorname{IgA}$ levels, as well as rheumatoid factor (RF) autoantibodies ${ }^{3}$. These findings reiterate evidence from a small exploratory study of patients with ACPA-positive early RA and undifferentiated arthritis, in whom ABA treatment also reduced autoantibody levels ${ }^{5}$. These circulating disease-associated autoantibodies, a central hallmark of RA, are believed to primarily arise from autoreactive B cells in the hyperplastic synovia of affected joints ${ }^{6}$.

Patients with ACPA-positive RA in fact may have better responses with ABA treatment as compared to ACPA-negative patients ${ }^{7}$. Scarsi, et al found that ABA treatment also normalized the RA-associated increases in levels of free light chains ${ }^{3}$, a marker of dysregulated immuno-globulin production commonly seen in multiple myeloma, as well as in RA and systemic lupus erythematosus (SLE). Taken together, these new data suggest that ABA treatment restores regulation within the memory $\mathrm{B}$ cell compartment, and these treatment effects lead to a compensatory surge in levels of naive B cells at 6 months ${ }^{3}$.

While ABA may also affect professional antigen-presenting cells (APC) of the myeloid series that are important drivers of RA pathogenesis, the earliest murine experimental models showed that CTLA-4 Ig had in vivo effects on both activated $\mathrm{T}$ cells and $\mathrm{B}$ cells ${ }^{8}$. These findings suggested that ABA treatment might dampen the co-stimulatory interaction between $\mathrm{T}$ and $\mathrm{B}$ lymphocytes, leading to amelioration of autoimmunity-driven inflammation. Memory B cells expressing CD80/86 may be especially efficient APC for the recruitment and maintenance of antigen-specific memory and effector $\mathrm{T}$ cells ${ }^{9}$. CD80/86 may also mediate pro-survival signals for APC. In an earlier synovial biopsy study, ABA treatment had the greatest effects on B cell representation in affected joints, because those cells rapidly disappeared from the RA synovium ${ }^{10}$. These findings contribute to an emerging perspective that biologic agents that act through very different primary

See Abatacept affects B cells and antibodies, April issue, page 666

Personal non-commercial use only. The Journal of Rheumatology Copyright ( 2014. All rights reserved. 
targets to provide clinical benefits for patients with RA may display common immunoregulatory effects that normalize the $\mathrm{B}$ cell defects in $\mathrm{RA}^{11,12}$.

\section{RTX and B Cell Modulation}

In many ways, the immunologic outcome of $\mathrm{ABA}$ treatment is highly reminiscent of the effect of B cell-targeted therapy with RTX, which initially causes marked peripheral blood B cell depletion. At 6 months, clinical response rates for RTX are very similar to those of $\mathrm{ABA}$ and for tumor necrosis factor (TNF) inhibitors. When serum levels of the RTX antibody wane after many months, there is a return of circulating blood B lymphocytes due to repopulation of the peripheral compartment. In patients with more prolonged clinical responses after single RTX treatments, levels of CD27+IgD+ (unswitched) B cells and CD27+IgD- (switched) $\mathrm{B}$ cells were higher in those who experienced an early relapse than in patients who experienced a late relapse ${ }^{13,14}$. During the earliest phase of peripheral reconstitution, there are heightened levels of transitional B cells that are presumably newly generated in the bone marrow. However, within weeks there is a shift to naive mature B cells that may reflect a resetting of the adaptive immune system that is associated with longer periods of treatment-induced clinical benefits ${ }^{13,14}$. Hence, akin to the findings with ABA, anti-CD20 therapy induces clinical responses linked to lower levels of activated B cells and memory B cells ${ }^{13,15}$ as well as modest decreases in ACPA and RF autoantibody levels ${ }^{13,16}$.

\section{TNF Blockade and B Cell Modulation}

TNF inhibitors have been approved for the treatment of RA since 1998, and clinical efficacy attained with these agents has become the yardstick by which we currently judge all other agents. While there are now 5 different approved TNF inhibitors, with nuances in their designs, modes of administration, and treatment regimens, these all have generally comparable clinical response rates and safety profiles.

The physiology of B cell proliferation is known to involve the tightly regulated expression of TNF, and hence dysregulated TNF production has been implicated as a cause of the $\mathrm{B}$ cell abnormalities commonly found in patients with RA ${ }^{17,18}$. This may explain why treatment with the anti-TNF antibody infliximab also results in decreases in blood pre-switched memory $\mathrm{B}$ cell numbers with compensatory increases in peripheral blood transitional and naive $\mathrm{B}$ cells ${ }^{17,19}$.

Etanercept (ETN) represents a recombinant fusion protein of a human TNF receptor (TNFR II p75) with an IgG constant region to increase in vivo half-life, and in vivo ETN acts as a decoy receptor that blocks both TNF- $\alpha$ and lymphotoxin $\beta$, a factor linked to ectopic lymphoid tissue formation. Anolik and colleagues have reported that ETN treatment results in normalized memory B cell levels and an increase in the proportion of transitional B cells and naive B cells due to effects on lymphoid germinal centers, in which immune complexes arrayed on follicular dendritic cells are involved in $\mathrm{B}$ cell clonal selection ${ }^{20}$. Therefore, during RA pathogenesis, the defects in $\mathrm{B}$ cell tolerance may be reversed by TNF inhibitors, which suggests these are linked to inflammation.

\section{Interleukin 6 (IL-6) Blockade and B Cell Dysregulation} The anti-IL-6 receptor agent tocilizumab (TCZ) has also become a major resource for the treatment of RA. IL-6 has diverse and protean effects on many cell types, involved in both homeostatic and inflammatory pathways. This cytokine was first identified as a B cell growth factor that contributes to differentiation of B cells into plasma cells, the antibody-producing factories of the body ${ }^{21}$. In patients with RA, TCZ is another agent that has a dramatic effect on B lineage cells, with decreases in levels of circulating switched and unswitched memory B cells and with overall decreases in measured levels of antibody gene hypermutation in blood B cells ${ }^{22,23}$. However, it has little or no effect on IgG levels. In a study of 15 patients with SLE, similar effects of TCZ treatment have been documented in circulating B cell subsets after 12 weeks of IL- 6 receptor blockade, as the frequency of $\mathrm{CD} 27^{\mathrm{HIGH}} \mathrm{CD} 38^{\mathrm{HIGH}} \mathrm{IgD}$-plasmablasts/plasma cells and IgD-CD27+ post-switched memory B cells, as well as $\mathrm{IgG}+$ memory B cells, declined ${ }^{24}$. Conversely, TCZ treatment also increased the frequency of $\operatorname{IgD}+\mathrm{CD} 27$ antigen-inexperienced B cells. The levels of CD38 mature naive $B$ cells increased significantly. These changes were concurrent with decreases in activated lymphocytes, and the frequency of CD4+CD45RA+CCR7+ naive T cells also increased ${ }^{24}$.

\section{B Cell Activation Factor (BAFF) Blockade Mechanism of Action Is Different}

Not all agents that target B cell pathways bring about the same immunomodulatory effects and clinical benefits for patients with RA. The TNF family member (TNFSF13) BAFF, also called B lymphocyte stimulator (BLyS), serves essential functions in B cell survival and maturation during early antigen-independent phases in the bone marrow or after transitional $\mathrm{B}$ cells traffic and differentiate into mature antigen-naive B cells in the periphery. BAFF also supports the end-differentiation of plasma blasts and plasma cells ${ }^{25}$ Notably, BAFF blockade has very different effects on the distribution of human B cell subsets in the bloodstream than other biologic agents, as described above, and these same patterns have been seen with the anti-BAFF antibody belimumab, as well as the more recently developed anti-BAFF antibody tabalumab, and the decoy receptor TACI-Ig (atacicept). Indeed, in contrast to the seemingly consistent immunomodulatory effects described above with RTX, TNF inhibitors, IL-6 R blockade, and now described with CTLA4-Ig (ABA), BAFF blockade instead causes increases in blood levels of memory B cells, which after

Personal non-commercial use only. The Journal of Rheumatology Copyright (C) 2014. All rights reserved. 
several months return to pretreatment levels ${ }^{26,27}$. Most importantly, BAFF blockade attained with agents of various designs ${ }^{28,29}$ has not provided the level of clinical benefits in RA seen with other currently approved biologic agents. Nonetheless, BAFF blockade has proven clinical benefits in $\mathrm{SLE}^{30}$, which on the other hand suggests that B cells play very different roles in the immunopathogenesis of these diseases.

There is now extensive evidence that diverse biologic agents can provide clinical benefits associated with shifts in the B cell compartment of the adaptive immune system in patients with RA. Intriguingly, these shared features of effective biologic agents for normalization of peripheral blood memory B cell levels are commonly concordant with increases in naive $\mathrm{B}$ cells and reductions in disease-associated serum autoantibodies. It remains controversial whether these changes are directly responsible for clinical benefits, and whether the known alterations or deficiencies in B cell clonal selection and trafficking are main drivers of the disease. Yet not all approaches to target $B$ cells are equally effective in RA; there are now results from clinical trials showing that several different anti-BAFF/BLyS agents all demonstrated a lack of efficacy in RA, a finding that in part further highlights the differences between RA and SLE immunopathogenesis.

As for the mechanism of action of $\mathrm{ABA}$, mounting evidence now suggests that beneficial therapeutic effects are most probably related to interference with the bidirectional interactions involving $\mathrm{T}$ cell-mediated stimulation of pathogenic B cells. More importantly, there is much data to suggest that the inflammatory environment of RA may be a major contributor to activation and even inappropriate prosurvival effects on post-germinal center B cells. This influence may stoke the self-perpetuating immune response in RA and be part of the defect in immune tolerance that contributes to inflammatory synovitis, which in turn contributes to further $\mathrm{B}$ cell defects. While defects in peripheral immune tolerance checkpoints have been described in patients with $\mathrm{RA}^{19}$, it remains controversial whether these defects are primary to the disease or in fact represent a byproduct induced by cytokine imbalances ${ }^{18}$. Plasma cell populations can become expanded in certain disease states because of an increase in the survival niches in affected inflamed tissues. The central lesson may be that efficacy in RA appears to require treatment-induced normalization of disease-associated B cell defects.

GREGG J. SILVERMAN, MD; Departments of Medicine and Pathology; ADAM PELZEK, MSc;

Department of Pathology, New York University, New York, New York, USA.

Address correspondence to Dr. G. Silverman, Department of Medicine, NYU School of Medicine, 450 E. 29th St., New York, New York 10016, USA.E-mail: Gregg.Silverman@nyumc.org

\section{REFERENCES}

1. Conaghan PG, Durez P, Alten RE, Burmester GR, Tak PP, Klareskog L, et al. Impact of intravenous abatacept on synovitis, osteitis and structural damage in patients with rheumatoid arthritis and an inadequate response to methotrexate: the ASSET randomised controlled trial. Ann Rheum Dis 2013;72:1287-94.

2. Pieper J, Herrath J, Raghavan S, Muhammad K, Vollenhoven R, Malmstrom V. CTLA4-Ig (abatacept) therapy modulates T cell effector functions in autoantibody-positive rheumatoid arthritis patients. BMC Immunology 2013;14:34.

3. Scarsi M, Paolini L, Ricotta D, Pedrini A, Piantoni S, Caimi L, et al. Abatacept reduces levels of switched memory B cells, autoantibodies, and immunoglobulins in patients with rheumatoid arthritis. J Rheumatol 2014;41:666-72.

4. Bar-Or A, Oliveira EM, Anderson DE, Krieger JI, Duddy M, O'Connor KC, et al. Immunological memory: contribution of memory B cells expressing costimulatory molecules in the resting state. J Immunol 2001;167:5669-77.

5. Emery P, Durez P, Dougados M, Legerton CW, Becker JC, Vratsanos G, et al. Impact of T-cell costimulation modulation in patients with undifferentiated inflammatory arthritis or very early rheumatoid arthritis: a clinical and imaging study of abatacept (the ADJUST trial). Ann Rheum Dis 2010;69:510-6.

6. Amara K, Steen J, Murray F, Morbach H, Fernandez-Rodriguez BM, Joshua V, et al. Monoclonal IgG antibodies generated from joint-derived B cells of RA patients have a strong bias toward citrullinated autoantigen recognition. J Exp Med 2013;210:445-55.

7. Gottenberg JE, Ravaud P, Cantagrel A, Combe B, Flipo RM, Schaeverbeke T, et al. Positivity for anti-cyclic citrullinated peptide is associated with a better response to abatacept: data from the 'Orencia and Rheumatoid Arthritis' registry. Ann Rheum Dis 2012;71:1815-9.

8. Finck BK, Linsley PS, Wofsy D. Treatment of murine lupus with CTLA4Ig. Science 1994;265:1225-7.

9. Kroeger DR, Rudulier CD, Bretscher PA. Antigen presenting B cells facilitate CD4 T cell cooperation resulting in enhanced generation of effector and memory CD4 T cells. PLoS One 2013;8:e77346.

10. Buch MH, Boyle DL, Rosengren S, Saleem B, Reece RJ, Rhodes LA, et al. Mode of action of abatacept in rheumatoid arthritis patients having failed tumour necrosis factor blockade: a histological, gene expression and dynamic magnetic resonance imaging pilot study. Ann Rheum Dis 2009;68:1220-7.

11. Daridon C, Burmester GR, Dorner T. Anticytokine therapy impacting on B cells in autoimmune diseases. Curr Opin Rheumatol 2009;21:205-10.

12. Modi S, Soejima M, Levesque MC. The effect of targeted rheumatoid arthritis therapies on anti-citrullinated protein autoantibody levels and B cell responses. Clin Exp Immunol 2013;173:8-17.

13. Roll P, Dorner T, Tony HP. Anti-CD20 therapy in patients with rheumatoid arthritis: predictors of response and B cell subset regeneration after repeated treatment. Arthritis Rheum 2008;58:1566-75.

14. Silverman GJ, Boyle DL. Understanding the mechanistic basis in rheumatoid arthritis for clinical response to anti-CD20 therapy: the B-cell roadblock hypothesis. Immunol Rev 2008;223:175-85.

15. Nakou M, Katsikas G, Sidiropoulos P, Bertsias G, Papadimitraki E, Raptopoulou A, et al. Rituximab therapy reduces activated B cells in both the peripheral blood and bone marrow of patients with rheumatoid arthritis: depletion of memory B cells correlates with clinical response. Arthritis Res Ther 2009;11:R131.

16. Cambridge G, Leandro MJ, Edwards JC, Ehrenstein MR, Salden M, Bodman-Smith M, et al. Serologic changes following B lymphocyte depletion therapy for rheumatoid arthritis. Arthritis

Personal non-commercial use only. The Journal of Rheumatology Copyright $@$ $\subset$ 2014. All rights reserved. 
Rheum 2003;48:2146-54.

17. Souto-Carneiro MM, Mahadevan V, Takada K, Fritsch-Stork R, Nanki T, Brown M, et al. Alterations in peripheral blood memory B cells in patients with active rheumatoid arthritis are dependent on the action of tumour necrosis factor. Arthritis Res Ther 2009; 11:R84.

18. Catalan D, Aravena O, Sabugo F, Wurmann P, Soto L, Kalergis $\mathrm{AM}$, et al. B cells from rheumatoid arthritis patients show important alterations in the expression of CD86 and FcgammaRIIb, which are modulated by anti-tumor necrosis factor therapy. Arthritis Res Ther 2010;12:R68.

19. Menard L, Samuels J, Ng YS, Meffre E. Inflammation-independent defective early B cell tolerance checkpoints in rheumatoid arthritis. Arthritis Rheum 2011;63:1237-45.

20. Anolik JH, Ravikumar R, Barnard J, Owen T, Almudevar A, Milner $\mathrm{EC}$, et al. Cutting edge: anti-tumor necrosis factor therapy in rheumatoid arthritis inhibits memory B lymphocytes via effects on lymphoid germinal centers and follicular dendritic cell networks. J Immunol 2008;180:688-92.

21. Muraguchi A, Nishimoto H, Kawamura N, Hori A, Kishimoto T. B cell-derived BCGF functions as autocrine growth factor(s) in normal and transformed B lymphocytes. J Immunol 1986; 137:179-86.

22. Muhammad K, Roll P, Seibold T, Kleinert S, Einsele H, Dorner T, et al. Impact of IL-6 receptor inhibition on human memory B cells in vivo: impaired somatic hypermutation in preswitch memory $\mathrm{B}$ cells and modulation of mutational targeting in memory B cells. Ann Rheum Dis 2011;70:1507-10.

23. Roll P, Muhammad K, Schumann M, Kleinert S, Einsele H, Dorner $\mathrm{T}$, et al. In vivo effects of the anti-interleukin- 6 receptor inhibitor tocilizumab on the B cell compartment. Arthritis Rheum 2011;63:1255-64.

24. Shirota Y, Yarboro C, Fischer R, Pham TH, Lipsky P, Illei GG. Impact of anti-interleukin-6 receptor blockade on circulating $T$ and B cell subsets in patients with systemic lupus erythematosus. Ann Rheum Dis 2013;72:118-28.
25. Scholz JL, Cancro MP. Resolve, revise, and relax: the 3 Rs of B cell repertoire adjustment. Immunology Lett 2012;143:2-8.

26. Wallace DJ, Stohl W, Furie RA, Lisse JR, McKay JD, Merrill JT, et al. A phase II, randomized, double-blind, placebo-controlled, dose-ranging study of belimumab in patients with active systemic lupus erythematosus. Arthritis Rheum 2009;61:1168-78.

27. Tak PP, Thurlings RM, Rossier C, Nestorov I, Dimic A, Mircetic V, et al. Atacicept in patients with rheumatoid arthritis: results of a multicenter, phase Ib, double-blind, placebo-controlled, dose-escalating, single- and repeated-dose study. Arthritis Rheum 2008;58:61-72.

28. Genovese MC, Kinnman N, de La Bourdonnaye G, Pena Rossi C, Tak PP. Atacicept in patients with rheumatoid arthritis and an inadequate response to tumor necrosis factor antagonist therapy: results of a phase II, randomized, placebo-controlled, dose-finding trial. Arthritis Rheum 2011;63:1793-803.

29. Genovese M, Silverman J, Emery P, Gupta R, Gill A, Komocsar WJ, et al. Efficacy and safety of subcutaneous administration of tabalumab, an anti-B cell activating factor monoclonal antibody, in rheumatoid arthritis: results from a phase 3 multicenter, randomized, double-blind study [abstract]. Arthritis Rheum 2013;65 Suppl 10:S733.

30. Manzi S, Sanchez-Guerrero J, Merrill JT, Furie R, Gladman D, Navarra SV, et al. Effects of belimumab, a B lymphocyte stimulator-specific inhibitor, on disease activity across multiple organ domains in patients with systemic lupus erythematosus: combined results from two phase III trials. Ann Rheum Dis 2012;71:1833-8

J Rheumatol 2014;41:825-8; doi:10.3899/jrheum.140022 